\title{
Influence of variety and growing location on carotenoid and vitamin $E$ contents of 184 different durum wheat varieties (Triticum turgidum ssp. durum) in Germany
}

\author{
Sabrina Groth ${ }^{1,2} \cdot$ Ramona Wittmann $^{2} \cdot$ C. Friedrich H. Longin ${ }^{3} \cdot$ Volker Böhm $^{2}$
}

Received: 4 April 2020 / Revised: 20 June 2020 / Accepted: 28 June 2020 / Published online: 11 July 2020

(c) The Author(s) 2020

\begin{abstract}
The influence of variety and growing location on the carotenoid and vitamin E content of 184 different varieties of durum wheat of each of the German locations Hohenheim and Seligenstadt was analyzed by HPLC. In addition, the yellow pigment content was measured as $b$ value using a chroma meter. The results showed that the measured parameters vary both between sites and varieties, with higher variance between varieties. Finally, we elaborated a high genetic variance and heritability for lutein and total carotenoids and no negative correlations to important agronomic and quality traits in durum wheat. Thus, future durum breeding could produce varieties with improved agronomy, quality, and increased contents of lutein and total carotenoids. Vitamin $\mathrm{E}$ has only a minor importance due to the low contents in durum wheat. Due to the high correlation between the $b$ value and the total carotenoid content, the $b$ value could be used as a cheap and rapid method to initially screen high numbers of breeding lines before testing individual promising breeding lines with HPLC, warranting efficient and accurate selection of durum lines with increased carotenoid content.
\end{abstract}

Keyword Optimized extraction $\cdot$ Lutein $\cdot$ Tocopherols $\cdot$ HPLC $\cdot b$ Value $\cdot$ Genetic variability

$\begin{array}{ll}\text { Abbreviations } \\ \text { AMD } & \text { Age-related macular degeneration } \\ \text { a.s.l. } & \text { Above sea level } \\ \text { BLUE } & \text { Best linear unbiased estimates } \\ \text { BLUP } & \text { Best linear unbiased predictors } \\ \text { MtBE } & \text { Methyl tert-butyl ether } \\ \text { REML } & \text { Restricted maximum-likelihood } \\ \text { TKM } & \text { Thousand kernel mass }\end{array}$

Electronic supplementary material The online version of this article (https://doi.org/10.1007/s00217-020-03557-1) contains supplementary material, which is available to authorized users.

Volker Böhm

volker.boehm@uni-jena.de

1 Hamburg School of Food Science, Institute of Food Chemistry, University of Hamburg, Grindelallee 117, 20146 Hamburg, Germany

2 Institute of Nutritional Sciences, Friedrich Schiller University Jena, Dornburger Straße 25-29, 07743 Jena, Germany

3 State Plant Breeding Institute, University of Hohenheim, Fruwirthstraße 21, 70599 Stuttgart, Germany

\section{Introduction}

Durum wheat (Triticum turgidum ssp. durum) is particularly suitable for the production of pasta and is in this form of importance for human nutrition [1]. In Germany, per capita consumption of pasta is approximately $8.7 \mathrm{~kg}$ per year, but in other countries much larger (e.g., Italy $>25 \mathrm{~kg}$ ) [2-4]. In addition to complex carbohydrates, which are especially important for meeting energy needs, pasta contains proteins and other important minor components like vitamins, minerals, fiber, and phytochemicals, especially in the whole grain version [1]. Carotenoids, belonging to the group of phytochemicals, determine the yellow pigment content in cereals which, together with a number of other parameters, is an important criteria for its quality [5].

With regard to the human organism, carotenoids and vitamin E, in particular in their capacity as antioxidants, play an important role. These substances may delay, slow down, or prevent oxidation of molecules present in the body [6]. The reaction of free radicals, which cause damage to macromolecules such as DNA or lipids in the organism and play an important role in the pathogenesis of various diseases, is delayed or prevented by antioxidants [7]. 
T. durum contains higher amounts of the two carotenoids lutein and zeaxanthin; these are also part of the macula lutea, the point of sharpest vision on the retina in the human eye $[8,9]$. There, lutein and zeaxanthin act as antioxidants and absorb high-energy light that can damage the retina [10-13]. Human intervention studies have shown that increased dietary intake of lutein can delay the development of agerelated macular degeneration (AMD), which can lead to serious vision problems [10, 14-16]. Furthermore, involvement of lutein in the maintenance of cognitive abilities in old age is discussed [17]. On the basis of further studies, chemo-preventive effects of lutein on breast cancer cells have been demonstrated, so that their use as a supplement to chemotherapy is currently being discussed [18-20]. In its function as antioxidants, tocochromanols are of importance in certain clinical pictures in which oxidative stress plays a role. Protective effects have already been discussed in cardiovascular diseases, atherosclerosis, Alzheimer's disease, and cancer [21,22].

In Germany, both winter-hardy and frost-sensitive durum wheat varieties are cultivated, although only the summer varieties 'Duramant', 'Durasol', and 'Fulgur' and the winter variety 'Wintergold' are approved by the Bundessortenamt. In 2018, 11 summer and 6 winter varieties were released for cultivation in Europe [23].

The production of durum wheat in Germany is limited, so, to cover the need for $T$. durum for pasta production, about $80 \%$ is imported from abroad, especially from Canada, the USA, and southern Europe. In addition, transport has a negative environmental impact $[24,25]$. Germany as an importer, thus, depends on cultivation in other countries and the fluctuations in quantity and quality there. If $T$. durum has the right variety and location, Germany can strengthen its local cultivation and thus exert more influence on quality, the significance of which is becoming increasingly important. This implies, among other things, the analysis of durum wheat varieties for quality parameters and growing location suitability.

Studies have been carried out that have investigated the carotenoid and tocopherol contents of various durum wheat varieties depending on the cropping location. In this case, significant differences in the levels were found between varieties but also between production sites. For the ripening of the grains, dry, warm summers are an advantage as they favor a high vitreousity, which is considered a quality criterion [24-26]. In T. monococcum, a genetically related crop to $T$. durum, significantly different levels of lutein were observed in 6 consecutive years at the same site. The differences were, therefore, attributed to climatic conditions: low levels of lutein were measured when the summer months were particularly dry and warm. Significant differences in lutein content were also demonstrated at different sites and in different varieties [9].
However, all these studies investigated only few different varieties. In contrast, we used 184 winter durum varieties representing the actual elite germplasm in Central European durum wheat. In a previous publication, we measured a lot of important quality parameters of the winter durum varieties $[27,28]$. Our aims in the current study were to (1) develop a high-throughput method for quantification of carotenoids and vitamin E, (2) determine the genetic variability for lutein, zeaxanthin, tocopherols, and tocotrienols in durum wheat, and (3) elaborate the potential of breeding durum varieties with increased phytochemicals for future human diet. We compared the contents of carotenoids and vitamin $\mathrm{E}$ of 184 winter durum varieties grown at two locations in Germany.

\section{Materials and methods}

\section{Chemicals}

All chemicals were of analytical grade. Ethanol absolute was from Merck KGaA (Darmstadt, Germany), butylated hydroxytoluene was purchased from Sigma-Aldrich Chemie GmbH (Taufkirchen, Germany), magnesium carbonate was from Honeywell Speciality Chemicals GmbH (Seelze, Germany) and sodium sulfate was from Carl Roth GmbH \& Co. KG (Karlsruhe, Germany). Solvents for chromatography were of HPLC quality. Methanol, methyl tert-butyl ether (MtBE), and tetrahydrofuran were used from Chemsolute, Th. Geyer GmbH \& Co. KG (Renningen, Germany), and $n$-hexane was purchased from VWR International GmbH (Darmstadt, Germany). The bidistilled water was obtained by a MicroPure purification system (Fisher Scientific GmbH, Schwerte, Germany).

The carotenoid standard substances $\beta$-apo- 8 '-carotenal as internal standard, lutein, and zeaxanthin were purchased from CaroteNature GmbH (Münsingen, Switzerland). Tocopherols $(\alpha-, \beta-, \gamma-, \delta-)$ were from Calbiochem (Darmstadt, Germany), tocotrienols $(\alpha-, \beta-, \gamma-, \delta$-) were purchased from Davos Life Sciences Pte Ltd (Singapore), and $\alpha$-tocopherol acetate (internal standard) was from Sigma Aldrich Chemie GmbH (Taufkirchen, Germany).

\section{Sample material}

For the determination of carotenoids and vitamin E, 184 samples of $T$. durum, grown in 2014 in Hohenheim (next to Stuttgart/Germany; N 48 42' 42", E009 12' 41"; $400 \mathrm{~m}$ a.s.l.) and 184 samples of the same genotype, grown in Seligenstadt (near Würzburg/Germany; N 49 ${ }^{\circ} 52^{\prime}$, E $010^{\circ} 8^{\prime} ; 269 \mathrm{~m}$ a.s.1.) were chosen. The origin of wheat varieties was in different countries in North America, and Southern and Northern Europe. The selection only included 
old and modern varieties that can be cultivated in Central-toEastern Europe, using the Central Europe panel (CP). The field trials have been characterized in detail by Sieber et al. and Rapp et al. [27, 28]. Each variety has been cultivated in two double rows in observation plots, which were $1.25 \mathrm{~m}$ long in a $\alpha$-lattice design with two replications and cropped under the conventional conditions with mineral fertilizer to achieve a nitrogen content of $200 \mathrm{~kg} / \mathrm{ha}$ and the use of herbicides, fungicides, and growth regulators according to farmers best practice.

The samples were packed as whole cereal grains in paper bags in an amount of $100 \mathrm{~g}$ per sample. The analyses were carried out using three aliquots from this batch. After the samples were delivered to the lab, they were stored at $4-6{ }^{\circ} \mathrm{C}$ under light protection in a refrigerator until analysis.

\section{Climate and soil}

Based on the data of the weather stations Seligenstadt (No. 7, district Würzburg) and Hohenheim (No. 103, city of Stuttgart), climatic diagrams were created (see Supplementary Fig. 1). The evaluation of rainfall, temperature, and sunshine duration was done for the period from October 2013 to July 2014 , since this was the cultivation period of the investigated durum wheat varieties. The two locations differed in terms of rainfall, significant differences were measured in October, May, and June. In May 2014, the rainfall in Seligenstadt was more than twice as high as in Hohenheim. The sum of rainfall in the period considered amounted to $531 \mathrm{~mm}$ in Hohenheim and $491 \mathrm{~mm}$ in Seligenstadt. Other differences between the sites were measured in terms of the duration of sunshine, especially in the period April-July, the months when durum wheat is growing. For the period considered, in Seligenstadt, $1700 \mathrm{~h}$ were recorded and in Hohenheim only $1529 \mathrm{~h}$. Both the monthly average temperatures and the types of soil of both locations did not differ significantly from each other [29].

\section{Extraction of carotenoids and vitamin E: development of an efficient processing method}

Based on an established method for the analysis of carotenoids and vitamin $\mathrm{E}$ in different foods using Ultra-Turrax (method according to Franke et al. [30]), a more efficient sample processing method for the analysis of the ingredients mentioned above in T. durum has been developed. The aim was to significantly reduce the time compared to the UltraTurrax method while maintaining the same high accuracy $(105.5 \pm 5.0 \%)$ and reproducibility (variation coefficient: $3.9 \pm 1.8 \%$ ) and to obtain a high level of comparability of the results. The average workload for one sample being extracted according to this method was $53 \mathrm{~min}$. First, some of the T. durum samples were analyzed using the established method for comparison purposes. $5 \mathrm{~g}$ of the sample were finely ground with a laboratory mill (IKA A10, IKA-Werke GmbH \& Co. KG, Staufen, Germany) and $5 \mathrm{~mL}$ of doubledistilled water was added to soak the ground sample. After $5 \mathrm{~min}$, the subsequent extraction was carried out by adding $35 \mathrm{~mL}$ of the solvent mixture methanol/tetrahydrofuran $(1+1, \mathrm{v} / \mathrm{v} ;+0.1 \%$ BHT, v/w $)$ and using an Ultra-Turrax (type T25, IKA-Werke GmbH \& Co. KG, Staufen, Germany). The supernatant was filtered under vacuum through filter paper No. 390 (Filtrak GmbH, Niederschlag, Germany) on a Büchner funnel. Here, three extractions were performed until the supernatant was colorless. The combined supernatants were concentrated in a rotary evaporator at $30 \pm 1{ }^{\circ} \mathrm{C}$ to a volume of about $1 \mathrm{~mL}$. The residue was dissolved in $10 \mathrm{~mL}$ ethanol absolute for the carotenoid analysis and in $n$-hexane/methyl tert-butyl ether $(98 / 2 ; \mathrm{v} / \mathrm{w})$ for the vitamin E analysis by HPLC.

As part of the method development, various extraction methods such as the use of a shaking incubator and an ultrasonic bath with the variation of various parameters were tried out and compared with the established method. The use of the ultrasonic bath for the extraction of carotenoids and vitamin $\mathrm{E}$ showed the highest extraction performance in comparison. Therefore, this method has been optimized and validated in a further step. The comparability of the results was assessed by means of a one-factorial analysis of variance (ANOVA) with a significance level of $p<0.05$ and showed no significant difference. The optimized sample processing method is described in the following section. Compared to the Ultra-Turrax method, the processing time per sample was reduced by about $34 \%$ and the consumption of the solvent methanol/tetrahydrofuran even by $71 \%$.

\section{Extraction of carotenoids and vitamin $\mathrm{E}$}

A quantity of about $20 \mathrm{~g}$ of the durum wheat grains was ground to a fine powder using a laboratory mill IKA A10 and $2 \mathrm{~g}$ of each sample were weighed in $50 \mathrm{~mL}$ tubes in triplicate. All examinations were performed under UV-protected light conditions. $2 \mathrm{~mL}$ of bidistilled water was added to the samples to reach a better extraction of the carotenoids and vitamin E derivatives. After $5 \mathrm{~min}$ of soaking, $200 \mathrm{mg}$ $\mathrm{MgCO}_{3}, 200 \mathrm{mg} \mathrm{Na}_{2} \mathrm{SO}_{4}, 10 \mathrm{~mL}$ methanol/tetrahydrofuran $(1+1, \mathrm{v} / \mathrm{v} ;+0.1 \%$ BHT, v/w), and the internal standards $\beta$-apo- 8 -carotenal $(200 \mu \mathrm{L} ; 1 \mathrm{mg} / \mathrm{mL})$ and $\alpha$-tocopherol acetate $(100 \mu \mathrm{L} ; 1 \mathrm{mg} / \mathrm{mL})$ were added to the samples. The extraction was carried out in an ultrasonic bath (Bandelin Sonorex RK 100, Bandelin electronic GmbH \& Co. KG, Berlin, Germany) for $15 \mathrm{~min}$ on ice to avoid heat-induced degradation of carotenoids and was repeated twice with $10 \mathrm{~mL}$ solvent each. Subsequently, the sample extracts were centrifuged for $5 \mathrm{~min}$ at $5000 \mathrm{rpm}$. The combined extracts were concentrated in the rotary evaporator at $30 \pm 1{ }^{\circ} \mathrm{C}$ for 
about $30 \mathrm{~min}$ to a small volume of approximately $1 \mathrm{~mL}$ and dissolved in $10 \mathrm{~mL}$ of ethanol absolute. Centrifugation (5 min, 14,000 rpm) was performed to remove particles from the extraction process before the carotenoids were analyzed by RP-HPLC-DAD. For the examination of vitamin E derivatives by NP-HPLC, the samples were dissolved in n-hexane/methyl tert-butyl ether $(98 / 2 ; \mathrm{v} / \mathrm{w})$.

\section{HPLC analysis of carotenoids}

The carotenoid contents in the samples were analyzed according to Ernawita et al. [31] using a RP-HPLC-DAD system from Merck Hitachi KGaA (Darmstadt, Germany): pump L-7100, autosampler L-7200, diode array detector L-7450, and interface D-7000. The separation was carried out on a Develosil RPAQUEOUS C30 $5 \mu \mathrm{m}(250 \times 4.6 \mathrm{~mm})$ column equipped with a C18 security guard $(4 \times 3.0 \mathrm{~mm})$ column (both from Phenomenex Ltd., Aschaffenburg, Germany). The column temperature was kept at $13 \pm 1{ }^{\circ} \mathrm{C}$. A binary gradient system with eluent (A) methanol and eluent (B) MtBE was used for the sample extracts and the standards, an injection volume of $50 \mu \mathrm{l}$ was used, and a flow rate of $1.0 \mathrm{~mL} / \mathrm{min}$ for a total run of $25 \mathrm{~min}$. The following gradient program (modified compared with [30]) was used: 0-20 min, linear gradient from $90 \%$ A to $70 \% \mathrm{~A} ; 20-25 \mathrm{~min}$, linear gradient from $70 \%$ A to $90 \%$ A. A diode array detector was used for the simultaneous monitoring $(450 \mathrm{~nm})$ of the different carotenoids. The identification of lutein and zeaxanthin was performed by comparing the retention times with those of external standards. To quantify the individual contents, five different dilutions of the standards were prepared in each case, and from this, a five-point calibration curve was generated. The linearity of the calibration lines was given. The limits of detection and quantification of the carotenoids were determined by the baseline noise signals by five times measurement of the solvent. The contents of carotenoids are given in $\mathrm{mg} / 100 \mathrm{~g}$ fresh weight.

\section{HPLC analysis of vitamin E}

Tocochromanols (tocopherols and tocotrienols) were determined according to Franke et al. [30] and analyzed on an NP-HPLC system from Merck Hitachi KGaA (Darmstadt, Germany): pump L-6200, autosampler AS-2000, fluorescence detector F-1080, and interface D-6000. The separation was carried out on a Vertex Eurospher 100-5 Diol $5 \mu \mathrm{m}$ $(250 \times 4.00 \mathrm{~mm})$ column equipped with a security guard (both from KNAUER GmbH, Berlin, Germany) and was heated to $35 \pm 1{ }^{\circ} \mathrm{C}$. The isocratic elution was carried out with $n$-hexane/methyl tert-butyl ether (98/2; v/w). An injection volume of $20 \mu \mathrm{L}$ was used for the sample extracts and the standards with a flow rate of $1.5 \mathrm{~mL} / \mathrm{min}$ and a total run of $45 \mathrm{~min}$. The detection of the various vitamin E derivatives was based on the fluorescent properties of the chromane ring with an excitation wavelength of $292 \mathrm{~nm}$ and an emission wavelength of $330 \mathrm{~nm}$ through a fluorescence detector. For the identification of the substances, their retention times were compared with those of the external standards. The quantification of the levels of the individual vitamin $\mathrm{E}$ derivatives was calculated using an eight-point calibration of the standards. The linearity of the calibration lines was given. The limits of detection and quantification of the vitamin $\mathrm{E}$ derivatives were determined by the baseline noise signals by five times measurement of the solvent. The contents of the various vitamin $\mathrm{E}$ derivatives are given in $\mathrm{mg} / 100 \mathrm{~g}$ fresh weight and the vitamin $\mathrm{E}$ content as a sum of all derivatives is additionally given in $\mu \mathrm{mol} / 100 \mathrm{~g}$ fresh weight.

\section{Measurement of the $b$ value}

The $b$ value is a quick measurement using the color measurement device Minolta chroma meter CR-400/410 (Konica Minolta Holdings K.K., Osaka, Japan) and indicates the yellow pigment content of semolina. There is no extraction necessary. The method, which is a well-known parameter used by the pasta industry to efficiently determine semolina potential for the production of bright yellow pasta, does not only measure the content of carotenoids in durum wheat but also further substances which contribute to the yellow color of semolina. The higher the $b$ value, the more yellow the durum wheat semolina was. The measuring accuracy is very high $[32,33]$.

\section{Other important quality parameters}

The protein content was determined by near-infrared spectroscopy [International Association for Cereal and Technology (ICC) standard method 159, Vienna, Austria]. The vitreousity was measured by near-infrared spectroscopy according to ICC standard method 129 (ICC, Vienna, Austria) and the thousand kernel weight (TKW) was estimated with a Marvin seed analyzer (GTA Sensorik GmbH, Neubrandenburg, Germany).

\section{Statistical analysis}

For the descriptive statistics, both locations were evaluated individually and together with regard to the content of individual substances and also for the total carotenoids and vitamin $\mathrm{E}$ content. In this case, the total carotenoids is the sum of lutein and zeaxanthin and the vitamin E content corresponds to the sum of the measured derivatives $\alpha$-tocopherol, $\beta$-tocopherol, $\alpha$-tocotrienol, and $\beta$-tocotrienol. Mean value, standard deviation, median, and standard error as well as the respective minimum and maximum have been determined. The evaluation of statistically significant differences 
attributable to the location was carried out on the basis of Mann-Whitney tests as there was no normal distribution. $T$ tests were carried out for individual varieties. The Levene test was first used to check homogeneity of variance. If this condition was not fulfilled for the $t$ test, the Welch test was used instead. SPSS was used to check whether there were linear correlations between the substances according to Pearson. Furthermore, it was checked whether there was a correlation between the carotenoids and the $b$ value.

All other data were analyzed according to the following statistical model: $y_{i k o}=\mu+g_{i}+\operatorname{loc}_{k}+e_{i k}$, where $y_{i k o}$ was the phenotypic observation for the $i$ th variety tested in the $k$ th location in the $o$ th incomplete block, $\mu$ was an intercept term, $g_{i}$ was the genetic effect of the $i$ th genotype, $\operatorname{loc}_{k}$ was the effect of the $k$ th location, $b_{k o}$ was the effect of the $o$ th incomplete block at the $k$ th location, and $e_{i k}$ was the residual. All effects were regarded as random. Variance components were determined by the restricted maximum-likelihood (REML) method assuming a random model and a heterogenic error for single locations using classical one-stage analyses [34]. Significance of variance component estimates was tested by model comparison with likelihood ratio tests in which halved $P$ values were used as approximation [35]. Heritability was calculated as $h^{2}=1-\frac{\vartheta}{\sigma_{G}^{2}}$, where $\vartheta$ is the mean variance of a difference of two best linear unbiased predictors (BLUP) and $\sigma_{G}^{2}$ the genetic variance [36, 37]. In addition, best linear unbiased estimates (BLUEs) across locations were estimated assuming fixed genetic effects. All analyses were performed with the statistical software R (R Development Core Team, 2016) and the software ASReml 3.0 [38].

\section{Results and discussion}

\section{$b$ value}

In the 368 durum wheat samples, the yellow pigment content was determined using a chroma meter, in which the $b$ value of the semolina was measured. This resulted in $b$ values of $24.4 \pm 3.1$. Depending on the variety, there were variations in the values, ranging from 10.7 to 31.5 .

\section{Carotenoids and vitamin E}

In the 368 durum wheat samples examined, the xanthophylls lutein and zeaxanthin were identified and quantified using RP-HPLC-DAD (see Supplementary Tables 1 and 2). By means of NP-HPLC, the vitamin E derivatives $\alpha$ - and $\beta$-tocopherol as well as $\alpha$ - and $\beta$-tocotrienol were detected and quantified (see Supplementary Tables 3 and 4). Further derivatives were not found. Figures 1 and 2 show examples
Table 1 Descriptive statistics of the carotenoid contents in $T$. durum samples

\begin{tabular}{llllll}
\hline \multicolumn{7}{c}{ Mean $\pm \mathrm{SD}$} & $\mathrm{SE}_{\mathrm{M}}$ & Median & Min & Max \\
\hline Lutein $(\mathrm{mg} / 100 \mathrm{~g})$ & & & & & \\
Hoh $(n=184)$ & $0.308 \pm 0.141$ & 0.006 & 0.290 & 0.050 & 0.800 \\
Sel $(n=184)$ & $0.225 \pm 0.097$ & 0.004 & 0.223 & 0.060 & 0.660 \\
Mean $(n=368)$ & $0.267 \pm 0.128$ & 0.004 & 0.248 & 0.030 & 0.800 \\
Zeaxanthin $(\mathrm{mg} / 100 \mathrm{~g})$ & & & & & \\
Hoh $(n=184)$ & $0.035 \pm 0.021$ & 0.001 & 0.026 & 0.010 & 0.100 \\
Sel $(n=184)$ & $0.044 \pm 0.041$ & 0.002 & 0.028 & 0.011 & 0.200 \\
Mean $(n=368)$ & $0.040 \pm 0.033$ & 0.001 & 0.027 & 0.010 & 0.200 \\
Total carotenoid content $(\mathrm{mg} / 100 \mathrm{~g})$ & & & \\
Hoh $(n=184)$ & $0.343 \pm 0.158$ & 0.007 & 0.323 & 0.060 & 0.880 \\
Sel $(n=184)$ & $0.269 \pm 0.110$ & 0.005 & 0.260 & 0.050 & 0.710 \\
Mean $(n=368)$ & $0.306 \pm 0.141$ & 0.004 & 0.281 & 0.050 & 0.880 \\
\hline
\end{tabular}

The total carotenoid content is composed of the contents of lutein and zeaxanthin

$S D$ standard deviation, $S E_{M}$ standard error of mean, min minimum, max maximum, Hoh Hohenheim, Sel Seligenstadt

of chromatograms of the carotenoid and vitamin E analysis, respectively.

Figure 3 shows the box whisker plots of carotenoid contents of T. durum samples, for lutein and zeaxanthin, respectively, depending on locations. For an overview of the descriptive statistics, see Table 1.

Table 1 presents an overview of the contents of lutein, zeaxanthin, and total carotenoids of the $T$. durum wheat samples separately for the two sites Hohenheim and Seligenstadt and as mean values for both locations. The total carotenoid content as well as the contents of lutein and zeaxanthin varied between the two sites whereby the lutein and the total carotenoid contents in the samples from Hohenheim were higher than in samples from Seligenstadt. Durum wheat grown in Hohenheim had lutein levels of $0.31 \pm 0.14 \mathrm{mg} / 100 \mathrm{~g}$, whereas the mean value in Seligenstadt was $0.23 \pm 0.10 \mathrm{mg} / 100 \mathrm{~g}$. The content of zeaxanthin in varieties grown in Seligenstadt was slightly higher than in samples from Hohenheim $(0.044 \pm 0.041 \mathrm{mg} / 100 \mathrm{~g}$ and $0.035 \pm 0.021 \mathrm{mg} / 100 \mathrm{~g}$ ). The mean total carotenoid content at the Hohenheim site was $0.34 \pm 0.16 \mathrm{mg} / 100 \mathrm{~g}$ and at Seligenstadt only $0.27 \pm 0.11 \mathrm{mg} / 100 \mathrm{~g}$. The proportion of lutein in the total carotenoid content was, on average, $86.8 \%$ (43-96\%). Accordingly, an average of $13.2 \%$ of the contained carotenoids were in the form of zeaxanthin.

The results obtained here confirmed studies already carried out. Acquistucci et al. and Ramachandran et al. have also analyzed the carotenoids of different $T$. durum varieties, also identifying lutein and zeaxanthin. Lutein was determined to be decisive for the total carotenoid content $[39,40]$.

As shown in Fig. 3 and Table 1, there is a high variance between varieties in total carotenoid, lutein, and 
Table 2 Comparison of the contents of total carotenoids in durum wheat with literature values

\begin{tabular}{|c|c|c|c|}
\hline \multirow[t]{2}{*}{ Variety } & \multicolumn{3}{|c|}{ Contents of total carotenoids $(\mathrm{mg} / 100 \mathrm{~g})$} \\
\hline & Literature & Hohenheim & Seligenstadt \\
\hline \multicolumn{4}{|c|}{ 'AC Navigator' (No. 145) } \\
\hline & $0.96-1.41^{44}$ & $0.39 \pm 0.07$ & $0.30 \pm 0.01$ \\
\hline \multicolumn{4}{|c|}{ 'Auradur' (No. 129) } \\
\hline & $0.34 \pm 0.07^{43}$ & $0.13 \pm 0.01$ & $0.25 \pm 0.00$ \\
\hline & $0.33 \pm 0.00^{49}$ & & \\
\hline \multicolumn{4}{|c|}{ 'Duramar' (No. 147) } \\
\hline & $0.54 \pm 0.01^{45}$ & $0.56 \pm 0.02$ & $0.35 \pm 0.02$ \\
\hline \multicolumn{4}{|c|}{ 'Elsadur' (No. 119) } \\
\hline & $0.36 \pm 0.08^{43}$ & $0.60 \pm 0.01$ & $0.38 \pm 0.03$ \\
\hline \multicolumn{4}{|c|}{ 'Karur' (No. 151) } \\
\hline & $0.30 \pm 0.05^{43}$ & $0.45 \pm 0.00$ & $0.31 \pm 0.01$ \\
\hline \multicolumn{4}{|c|}{ 'Lloyd' (No. 148) } \\
\hline & $0.20 \pm 0.01^{43}$ & $0.39 \pm 0.02$ & $0.55 \pm 0.02$ \\
\hline \multicolumn{4}{|c|}{ 'Logidur' (No. 50) } \\
\hline & $0.22 \pm 0.04^{43}$ & $0.37 \pm 0.01$ & $0.16 \pm 0.01$ \\
\hline & $0.21 \pm 0.01^{49}$ & & \\
\hline \multicolumn{4}{|c|}{ 'Lunadur' (No. 34) } \\
\hline & $0.20 \pm 0.05^{43}$ & $0.17 \pm 0.00$ & $0.21 \pm 0.01$ \\
\hline & $0.20 \pm 0.00^{49}$ & & \\
\hline \multicolumn{4}{|c|}{ 'Lupidur' (No. 95) } \\
\hline & $0.24 \pm 0.06^{43}$ & $0.40 \pm 0.01$ & $0.16 \pm 0.01$ \\
\hline \multicolumn{4}{|c|}{ 'Prowidur' (No. 82) } \\
\hline & $0.40 \pm 0.01^{50}$ & $0.20 \pm 0.01$ & $0.32 \pm 0.01$ \\
\hline & $0.37 \pm 0.01^{51}$ & & \\
\hline & $0.51 \pm 0.02^{51}$ & & \\
\hline \multicolumn{4}{|c|}{ 'Simeto' (No. 149) } \\
\hline & $0.34 \pm 0.01^{46}$ & $0.16 \pm 0.01$ & $0.12 \pm 0.00$ \\
\hline & $0.37 \pm 0.01^{51}$ & & \\
\hline & $0.25 \pm 0.01^{39}$ & & \\
\hline \multicolumn{4}{|c|}{ 'Wintergold' (No. 86) } \\
\hline & $0.33 \pm 0.06^{43}$ & $0.71 \pm 0.01$ & $0.42 \pm 0.04$ \\
\hline & $0.31 \pm 0.00^{49}$ & & \\
\hline
\end{tabular}

The contents of total carotenoids are composed of the contents of lutein and zeaxanthin

zeaxanthin contents. This is valid for both sites. The total carotenoid content varied between 0.06 and $0.88 \mathrm{mg} / 100 \mathrm{~g}$ in the samples from Hohenheim and between 0.05 and $0.71 \mathrm{mg} / 100 \mathrm{~g}$ in the samples growing in Seligenstadt. However, the variance between the individual varieties was higher than the variance between the two growing sites. Thus, there were large differences between the carotenoid contents of the different varieties, which means that varieties could be selected with an almost fourfold higher carotenoid content. The differences between the locations, i.e., environmental conditions such as duration of sunshine, amount of rain and average temperature, have only a minor role. These cannot be influenced by a farmer, but the variety can be chosen based on multiple field locations data to warrant a high environmental stability.

The results of the contents of total carotenoids of the durum wheat samples from the two German sites are basically comparable with other studies; a selection of certain varieties is shown in Table 2.

It was shown that the contents of lutein, zeaxanthin, and of the total carotenoids of all varieties were lower in total at the drier and sunnier location of Seligenstadt than in Hohenheim. However, there were differences with regard to individual varieties. In Seligenstadt, for example, lower contents of total carotenoids were measured for the varieties 'AC Navigator', 'Duramar', 'Elsadur', 'Karur', 'Logidur', 'Lupidur', 'Simeto', and 'Wintergold' than in Hohenheim. The varieties 'Auradur', 'Lloyd', 'Lunadur', and 'Prowidur', among others, behaved differently, as lower total carotenoid contents were found at the Hohenheim site, where higher rainfall and lower sunshine duration were recorded during the cultivation period.

Other research groups were also able to show that different site conditions, such as rainfall and temperature, had an influence on carotenoid contents and differences between varieties exist. Fratianni et al. observed an increase in xanthophyll contents by up to $20 \%$ due to drought stress which was also dependent on the variety. In the variety 'Simeto', they determined $0.34 \mathrm{mg} / 100 \mathrm{~g}$ total carotenoids. During cultivation in Hohenheim and Seligenstadt, the carotenoid contents reached only $0.16 \pm 0.01$ and $0.12 \pm 0.00 \mathrm{mg} / 100 \mathrm{~g}$. In the Italian growing area, the water supply of the plant was about $300 \mathrm{l} / \mathrm{m}^{2}$, whereas, in Germany, the rainfall during cultivation was between 500 and $600 \mathrm{l} / \mathrm{m}^{2}$. This partly explains the significant differences between the two growing countries [41]. The increase in xanthophyll levels due to drought stress in durum wheat was also confirmed by Turkish researchers. Keles et al. cultivated durum wheat under different climatic conditions and found that carotenoid contents were highest at temperatures of $30-40{ }^{\circ} \mathrm{C}$ [42]. The carotenoid content of 'Wintergold' at the Hohenheim site was more than twice as high as indicated in the literature. Here, too, an influence of environmental factors on the carotenoids can be assumed, since in the study by Ziegler et al., even the same varieties at the same location fluctuated in different years of cultivation [43]. The total carotenoid content of 'AC Navigator' was significantly higher in the Van Hung and Hatcher investigations than at the Hohenheim and Seligenstadt sites. With contents of $0.96-1.41 \mathrm{mg} / 100 \mathrm{~g}$ depending on the location in Canada, the samples with $0.39 \pm 0.07$ and $0.30 \pm 0.01 \mathrm{mg} / 100 \mathrm{~g}$ in Germany showed less than half of the carotenoid content [44]. This is based on the assumption that genetic causes were present, since the varieties originate from Canada and are probably better 
Fig. 1 RP-HPLC chromatogram of the carotenoid analysis. Sample no. 2, genotype 05 ETT RA 4 IN 11, cultivation location: Seligenstadt. Peak identifications: 1: lutein; 2: zeaxanthin; IS: internal standard $\beta$-apo8 'carotenal

Fig. 2 NP-HPLC chromatogram (only shown for $25 \mathrm{~min}$, $t_{\mathrm{R}}=25-45$ min: baseline only) of the vitamin $\mathrm{E}$ analysis.

Sample no. 105, genotype 6.047/02/02, cultivation location: Seligenstadt. Peak identifications; IS: internal standard $\alpha$-tocopherol acetate; 1 :

$\alpha$-tocopherol; 2: $\alpha$-tocotrienol;

3: $\beta$-tocopherol; 4 : $\beta$-tocotrienol
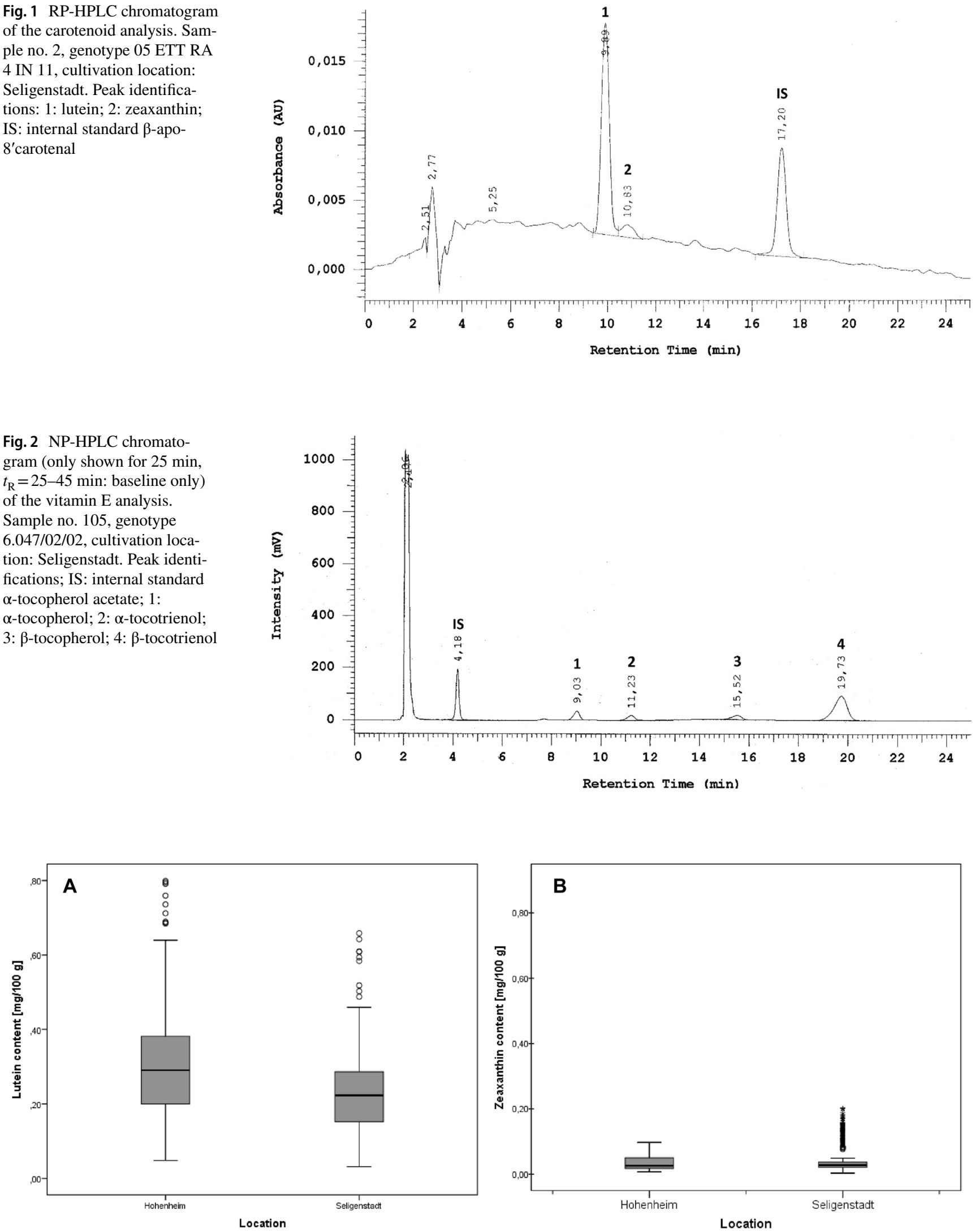

Fig. 3 Box-whisker plots of the carotenoid contents of the durum wheat samples at the Hohenheim $(n=184)$ and Seligenstadt $(n=184)$ sites. A: lutein content in $\mathrm{mg} / 100 \mathrm{~g}$; B: zeaxanthin content in $\mathrm{mg} / 100 \mathrm{~g}$ 
adapted to conditions there. In Hohenheim, the 'Duramar' variety contained $0.56 \pm 0.02 \mathrm{mg} / 100 \mathrm{~g}$, which almost corresponded to the literature value of $0.54 \pm 0.01 \mathrm{mg} / 100 \mathrm{~g}$. It is possible that the conditions in Detmold (Germany), where the durum wheat was grown in the publication by Werner, and Hohenheim were similar, leading to comparable values. In Duramar from the Seligenstadt site, significantly fewer carotenoids were detected, confirming the influence of site factors [45].

The two varieties with the highest contents of carotenoids at Seligenstadt had the designations 6.009/03/03 (No. 74) and 6.035/02/01 (No. 85). With contents of about $0.65 \mathrm{mg} / 100 \mathrm{~g}$, they did not differ significantly between sites. It is, therefore, assumed that the carotenoid content of these two varieties is relatively stable against environmental influences. Therefore, they can be recommended for cultivation in agriculture.

Figure 4 shows the box whisker plots of $\beta$-tocotrienol, the main vitamin $\mathrm{E}$ derivative in the T. durum samples, as a function of location.

Table 3 gives an overview of the descriptive statistics of the vitamin E contents in the T. durum samples. Durum wheat reached slightly higher concentrations in Seligenstadt with $9.7 \pm 4.8 \mu \mathrm{mol} / 100 \mathrm{~g}$ than in Hohenheim, where the durum wheat varieties contained on average $7.6 \pm 3.0 \mu \mathrm{mol} / 100 \mathrm{~g}$ vitamin E. When looking at the distribution of the individual vitamin $\mathrm{E}$ isomers, it is striking that mainly $\beta$-tocotrienol was contained on average with $64 \%$ of the total vitamin $E$ content. With an average of $8 \%$ of the total vitamin $\mathrm{E}$ content, $\beta$-tocopherol was the isomer with the lowest proportion. $\alpha$-Tocotrienol and $\alpha$-tocopherol were contained on average with 10 and $18 \%$, respectively.

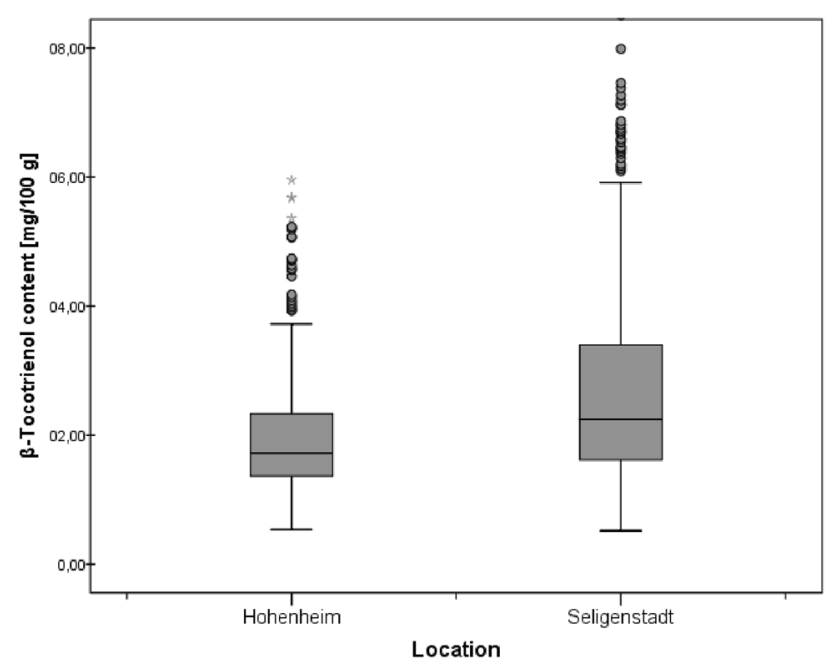

Fig. 4 Box-whisker plot of $\beta$-tocotrienol of the durum wheat samples at the Hohenheim and Seligenstadt site in $\mathrm{mg} / 100 \mathrm{~g}$
Table 3 Descriptive statistics of the vitamin E contents in T. durum samples

\begin{tabular}{|c|c|c|c|c|c|}
\hline & Mean \pm SD & $\mathrm{SE}_{\mathrm{M}}$ & Median & Min & Max \\
\hline \multicolumn{6}{|c|}{$\alpha$-Tocopherol (mg/100 g) } \\
\hline Hoh & $0.635 \pm 0.250$ & 0.011 & 0.568 & 0.310 & 1.690 \\
\hline Sel & $0.659 \pm 0.288$ & 0.012 & 0.608 & 0.090 & 1.900 \\
\hline Mean & $0.647 \pm 0.270$ & 0.008 & 0.584 & 0.090 & 1.900 \\
\hline \multicolumn{6}{|c|}{$\beta$-Tocopherol (mg/100 g) } \\
\hline Hoh & $0.247 \pm 0.116$ & 0.005 & 0.216 & 0.100 & 1.020 \\
\hline Sel & $0.312 \pm 0.169$ & 0.007 & 0.265 & 0.070 & 1.450 \\
\hline Mean & $0.279 \pm 0.148$ & 0.004 & 0.237 & 0.070 & 1.450 \\
\hline \multicolumn{6}{|c|}{$\alpha$-Tocotrienol (mg/100 g) } \\
\hline Hoh & $0.291 \pm 0.123$ & 0.005 & 0.255 & 0.120 & 0.790 \\
\hline Sel & $0.361 \pm 0.185$ & 0.008 & 0.327 & 0.060 & 1.130 \\
\hline Mean & $0.326 \pm 0.161$ & 0.005 & 0.279 & 0.060 & 1.130 \\
\hline \multicolumn{6}{|c|}{$\beta$-Tocotrienol (mg/100 g) } \\
\hline Hoh & $1.973 \pm 0.877$ & 0.037 & 1.725 & 0.540 & 5.950 \\
\hline Sel & $2.677 \pm 1.468$ & 0.062 & 2.243 & 0.520 & 8.830 \\
\hline Mean & $2.325 \pm 1.259$ & 0.038 & 1.949 & 0.520 & 8.830 \\
\hline \multicolumn{6}{|c|}{ Vitamin $\mathrm{E}(\mu \mathrm{mol} / 100 \mathrm{~g})$} \\
\hline Hoh & $7.630 \pm 2.98$ & 0.127 & 6.7300 & 3.280 & 20.84 \\
\hline Sel & $9.740 \pm 4.75$ & 0.202 & 8.3000 & 2.230 & 28.25 \\
\hline Mean & $8.690 \pm 4.10$ & 0.123 & 7.3700 & 2.230 & 28.25 \\
\hline
\end{tabular}

The vitamin $\mathrm{E}$ content is composed of the contents of $\alpha$-tocopherol, $\beta$-tocopherol, $\alpha$-tocotrienol, and $\beta$-tocotrienol

$S D$ standard deviation, $S E_{M}$ standard error of mean, min minimum, max maximum, Hoh Hohenheim, Sel Seligenstadt

The distribution of the isomers corresponds with investigations by Fratianni et al. and Lampi et al. According to this, $\beta$-tocotrienol and $\alpha$-tocopherol were most abundant in durum wheat $[26,41]$. Fratianni et al. and Hussain et al. have also identified $\beta$-tocotrienol as main vitamin $\mathrm{E}$ compound in different wheat species and T. durum, respectively, samples of different varieties [46, 47].

As with the carotenoid content, there was a high variance in vitamin $\mathrm{E}$ content between the varieties, which applies to both locations, see Fig. 4 and Table 3. The vitamin E content of the samples growing in Hohenheim varied between 3.28 and $20.84 \mu \mathrm{mol} / 100 \mathrm{~g}$ and in Seligenstadt between 2.23 and $28.25 \mu \mathrm{mol} / 100 \mathrm{~g}$. The variance between the individual varieties was also higher than the variance between the two growing locations. In the drier and sunnier location of Seligenstadt, a higher vitamin E content was found in the sum of all varieties. By appropriate variety selection, varieties with high vitamin $\mathrm{E}$ contents can be selected by breeding with a potential to increase 14-fold the content of total vitamin E.

With regard to the vitamin $\mathrm{E}$ contents of the durum wheat samples, there were differences to literature data and also between the two German sites, Table 4 shows a comparison of different varieties. 
Table 4 Comparison of the vitamin E contents in durum wheat with literature values

\begin{tabular}{llll}
\hline Variety & \multicolumn{2}{l}{ Vitamin E contents $(\mu \mathrm{mol} / 100 \mathrm{~g})$} \\
\cline { 2 - 4 } & Literature & Hohenheim & Seligenstadt \\
\hline 'Duramar' (No. 147) & & & \\
'Lloyd' (No. 148) & $16.74 \pm 0.89^{45}$ & $9.73 \pm 0.02$ & $23.53 \pm 1.80$ \\
& $12.75 \pm 0.12^{45}$ & $4.68 \pm 0.16$ & $15.93 \pm 0.78$ \\
& $09.24 \pm 0.90^{45}$ & & \\
'Prowidur' (No. 82) & & & \\
& $07.95 \pm 0.15^{45}$ & $6.17 \pm 0.23$ & $07.17 \pm 0.71$ \\
'Auradur' (No. 129) & $06.56 \pm 0.13^{45}$ & & \\
& $3.74 \pm 0.06^{43}$ & $1.86 \pm 0.02$ & $2.95 \pm 0.18$ \\
'Logidur' (No. 50) & $3.45 \pm 0.08^{43}$ & $2.53 \pm 0.03$ & $3.51 \pm 0.05$ \\
'Lunadur' (No. 34) & & & \\
& $2.92 \pm 0.08^{43}$ & $2.33 \pm 0.02$ & $2.66 \pm 0.07$ \\
'Simeto' (No. 149) & $3.61^{41} \pm 0.01$ & $2.78 \pm 0.12$ & $5.74 \pm 0.07$ \\
& & & \\
'Wintergold' (No. 86) & $4.64 \pm 0.10^{43}$ & $4.10 \pm 0.19$ & $3.99 \pm 0.26$ \\
\hline
\end{tabular}

The vitamin E content is composed of the contents of $\alpha$-tocopherol, $\beta$-tocopherol, $\alpha$-tocotrienol, and $\beta$-tocotrienol

The comparison with existing literature values showed that the vitamin $\mathrm{E}$ content of the different varieties was also influenced by environmental factors like the location and the conditions of the year of cultivation such as temperature and rainfall. It was shown that the drier and sunnier conditions of the Seligenstadt site led to a higher vitamin E content in the varieties 'Duramar', 'Lloyd', 'Prowidur', 'Auradur', 'Logidur', 'Lunadur', 'Simeto', and 'Wintergold', among others. Overall, there were large fluctuations in vitamin E levels in the literature and also between the two sites: the vitamin $\mathrm{E}$ contents of 'Duramar' and 'Llyod' varied strongly, whereas 'Prowidur' was less influenced by environmental conditions. According to Werner's publication, the vitamin E content of the 'Lloyd' variety grown in Detmold was between 9 and $13 \mu \mathrm{mol} / 100 \mathrm{~g}$ [45]. The differences between the locations were significantly higher with $15.9 \pm 0.8 \mu \mathrm{mol} / 100 \mathrm{~g}$ in durum wheat from Seligenstadt and $4.6 \pm 0.2 \mu \mathrm{mol} / 100 \mathrm{~g}$ in Hohenheim. This indicates that the vitamin E content of this variety is strongly influenced by environmental factors. In the case of the 'Auradur' variety, the vitamin E content at the Hohenheim site was $1.86 \pm 0.02 \mu \mathrm{mol} / 100 \mathrm{~g}$, which is about half of the literature value of $3.74 \pm 0.06 \mu \mathrm{mol} / 100 \mathrm{~g}$ [49]. The tocochromanol concentration of the variety at the Seligenstadt site was in between. The influence of environmental conditions became apparent. According to this, drier and sunnier conditions led to higher vitamin $\mathrm{E}$ contents.
Furthermore, Frattiani et al. observed in the 'Simeto' variety that the cultivation locations had different effects on the carotenoid and vitamin $\mathrm{E}$ contents of the same variety [41]. 'Simeto' is a durum wheat variety which already showed clear differences in carotenoid content between cultivation in Germany and Italy. In Italy, the lutein content was higher. At the Seligenstadt site, there were significantly more tocochromanols in durum wheat than when it was grown in Italy or Hohenheim [41]. The question therefore arises as to what conditions have triggered this development. This is because the vitamin E content in Hohenheim was even lower than in Italy, which suggests that it is not only climate and soil that play a role. These conditions were similar between Hohenheim and Seligenstadt; nevertheless, the content in Hohenheim with $2.78 \pm 0.12 \mu \mathrm{mol} / 100 \mathrm{~g}$ was significantly lower than in Seligenstadt with $5.74 \pm 0.07 \mu \mathrm{mol} / 100 \mathrm{~g}$. The content according to Fratianni et al. was in between. A major difference between the German and Italian locations was the amount of rainfall [41]. It is, therefore, assumed that both too much rain and too little rain lead to lower vitamin $E$ levels.

The variety 'Wintergold' had comparable vitamin E contents with the investigations of Ziegler et al. and, therefore, appeared to be more stable to environmental conditions than for example the varieties 'Auradur' or 'Simeto' [43]. Lampi et al. showed that the tocopherol contents of wheat varieties fluctuated to varying degrees depending on environmental influences [26]. Frattiani et al. observed that the tocotrienol contents increased by up to $15 \%$, the tocopherol contents by about $10 \%$ if the plants had only little water available [41]. Keleş et al. confirmed these results with $\alpha$-tocopherol, whose content increased during drought stress. However, a reverse effect was observed with heat stress; the contents of the tocopherol isomers decreased [42]. For the recommendation of durum wheat varieties for cultivation, those varieties were selected which on one hand had a high vitamin $\mathrm{E}$ content, and on the other hand, no significant differences in vitamin $\mathrm{E}$ content were found between the sites. This was the case for the varieties with the designations SZD 2884 (No. 142) and 6.029/07/01 (No. 159). The two varieties contained approximately 19 and $16 \mu \mathrm{mol} / 100 \mathrm{~g}$, respectively. Thus, at the Hohenheim site, they were ranked 2 and 5 of the highest vitamin $\mathrm{E}$ contents. In comparison with the Seligenstadt site, where vitamin E concentrations reached up to $28 \mu \mathrm{mol} / 100 \mathrm{~g}$ (variety Ankara 98, No. 183), this was significantly less. However, all these varieties with high contents showed a strong dependence on the location. Based on these results, only variety SZD 2884 is recommended for cultivation.

\section{Statistical evaluation}

Correlation analyses were performed based on the results of the quantitative determination of the contents of carotenoids and vitamin $\mathrm{E}$ of all samples. For the statistical 
comparison of the varieties depending on the location, the ten varieties with the highest levels of total carotenoids, lutein, and zeaxanthin were used, since only varieties with correspondingly high values are relevant for breeding. The comparison of the varieties revealed statistically significant differences depending on the location. Total carotenoid content was significantly higher in durum wheat from Hohenheim. This was also confirmed by the $t$ tests of the individual varieties, as only 6 out of 17 evaluated varieties had higher contents at the Seligenstadt site, only 4 of which were significant. Overall, the lutein content in durum wheat from Hohenheim was significantly higher than in Seligenstadt. Ten of sixteen evaluated varieties grown in Hohenheim had significant higher lutein contents than in Seligenstadt, two varieties showed no significant differences. When comparing the ten varieties with the highest zeaxanthin levels from each site, the $t$ test also showed significant differences for all varieties considered. Overall, the content between the two sites was significantly different according to the Mann-Whitney test, being higher in Seligenstadt. Here, 10 of 19 varieties from Seligenstadt showed significant higher zeaxanthin contents.

For the location comparison of the vitamin E contents, ten varieties with the highest contents were also evaluated. This revealed significant differences in maximum vitamin E levels for most varieties. The Mann-Whitney test showed that overall the levels in Seligenstadt were higher. From 19 varieties considered, the total content in 11 samples from Seligenstadt was significantly higher. Six varieties had significantly higher levels in Hohenheim than in Seligenstadt. The evaluation of the $\beta$-tocopherol concentrations showed that this was markedly increased in some varieties depending on the location. In most varieties the content at the Seligenstadt site was higher. Overall, the Mann-Whitney test revealed that durum wheat from Seligenstadt contained significantly more $\beta$-tocopherol than that from Hohenheim. In the evaluation of the individual varieties, the $\beta$-tocopherol content in Hohenheim was significantly higher in only 5 of the 18 selected; in two, no significant difference was observed.

\section{Correlation of carotenoid contents with vitamin E contents}

There were no significant correlations between the individual vitamin $\mathrm{E}$ isomers and zeaxanthin, with the exception of $\beta$-tocotrienol, with a very weak correlation $(R=0.067)$ (see Table 5). The investigation of the relationship of lutein with the tocochromanols revealed significant correlations for all vitamin $\mathrm{E}$ isomers. The correlation coefficients were between 0.071 and 0.190 , indicating that the relationship between the examined
Table 5 Correlations between the vitamin E contents and the contents of carotenoids

\begin{tabular}{lll} 
Correlation coefficient according to Pearson \\
\hline Lutein & Zeaxanthin & $\begin{array}{l}\text { Total } \\
\text { carotenoid } \\
\text { content }\end{array}$ \\
&
\end{tabular}

\begin{tabular}{llll}
\hline$\alpha$-Tocopherol & $0.133^{* *}$ & 0.041 n.s. & 0.131 n.s. \\
$\beta$-Tocopherol & $0.071^{*}$ & 0.015 n.s. & $0.068^{*}$ \\
$\alpha$-Tocotrienol & $0.190^{* *}$ & $0.067 *$ & $0.188^{* *}$ \\
$\beta$-Tocotrienol & $0.157 * *$ & 0.056 n.s. & $0.155^{* *}$ \\
$\sum$ Vitamin E & $0.163 * *$ & 0.057 n.s. & $0.161^{* *}$ \\
\hline
\end{tabular}

$* p<0.05$ : significant correlation; $* * p<0.01$ : very significant correlation; n.s.: not significant; the content of total carotenoids is composed of contents of lutein and zeaxanthin

Table 6 Correlations between contents of carotenoids and the $b$ value

\begin{tabular}{llll}
\hline & \multicolumn{3}{l}{ Correlation coefficient according to Pearson } \\
\cline { 2 - 4 } & Hohenheim & Seligenstadt & Both \\
\hline Lutein & $0.692^{* *}$ & $0.865^{* *}$ & $0.760^{* *}$ \\
Zeaxanthin & $0.312^{* *}$ & $0.142^{* *}$ & $0.154^{* *}$ \\
Total carotenoids & $0.662^{* *}$ & $0.817^{* *}$ & $0.727^{* *}$ \\
\hline
\end{tabular}

${ }^{* *} p<0.01$ : very significant correlation; the content of total carotenoids is composed of contents of lutein and zeaxanthin

compounds was classified as weak. This also applied to the sum of vitamin $\mathrm{E}$ isomers and the relationship between the total carotenoid contents and the tocochromanols.

\section{Correlations between $b$ values and carotenoids}

The yellow pigment content was determined using a chroma meter, in which the $b$ value of the semolina was measured. To investigate correlations between the yellow pigment contents and the contents of lutein, zeaxanthin, or total carotenoid, correlation analyses according to Pearson were performed. Table 6 and Fig. 5 show the corresponding correlation coefficients and correlations.

The correlation between $b$ values and contents of total carotenoids resulted in different correlation coefficients depending on the location. The coefficients were 0.662 , 0.817 , and 0.727 for the correlations of the contents of total carotenoids from Hohenheim, Seligenstadt, and both locations together. The linear correlation was more evident in Seligenstadt than in Hohenheim.

This relationship has already been described in the literature. Blanco et al. published correlation coefficients of 0.57 and 0.69 for the same correlation. However, they examined only two varieties [48]. Fratianni et al. found that the $b$ value has changed depending on the year of cultivation. In this context, the scientists received different correlation 

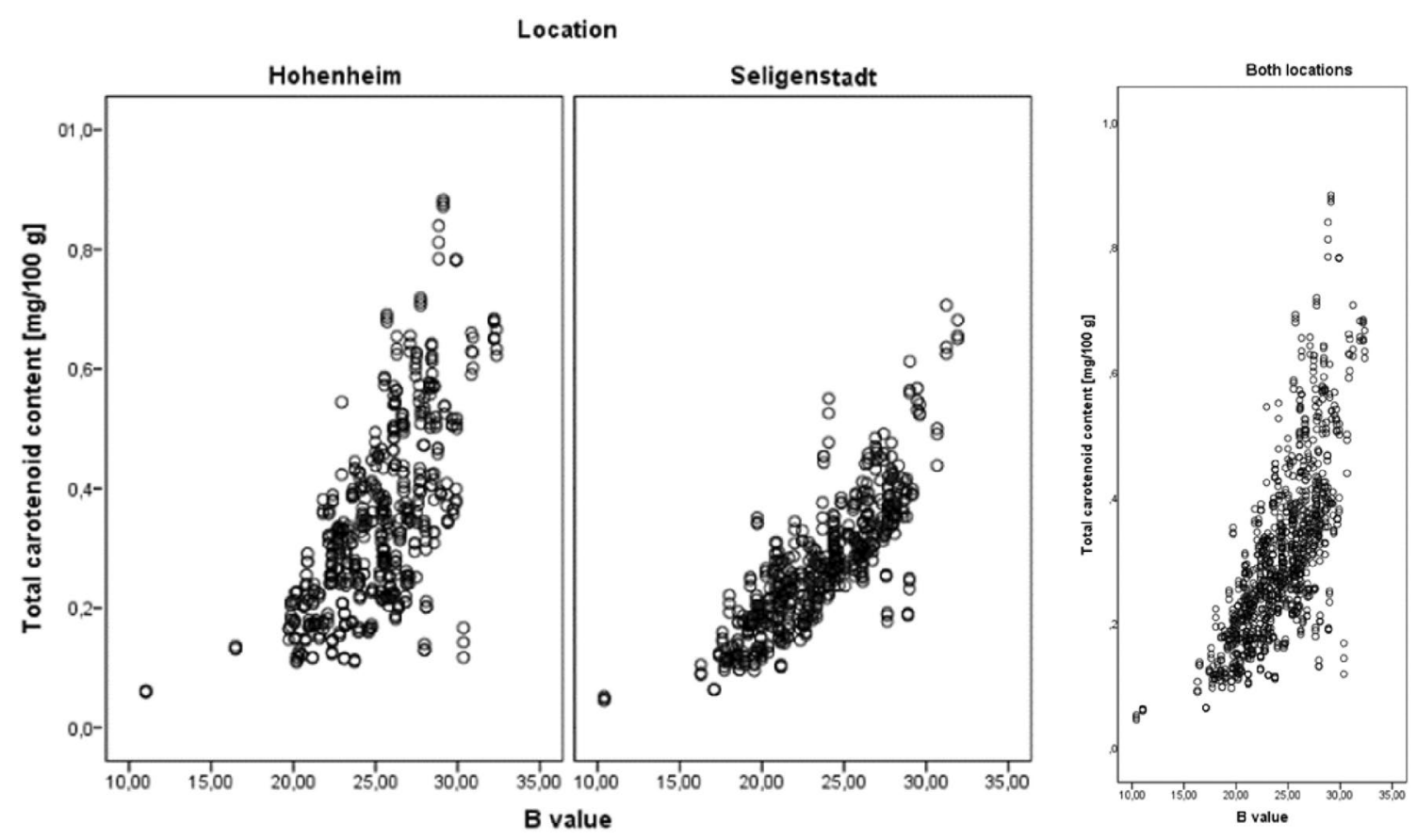

Fig. 5 Correlations between $b$ values and contents of total carotenoids

coefficients between $b$ values and lutein contents of 0.72 and 0.83 for 2 years [41]. These correlations are similar to those of the 184 samples, each with correlation coefficients of 0.692 and 0.865 for the locations Hohenheim and Seligenstadt. In the study of Fratianni et al., an increase in the $b$ value was not necessarily associated with an increase in the lutein content. The method was criticized for reducing the $b$ value regardless of the pigment content when there were dark spots in the semolina [41].

The high correlations between the $b$ values and the total carotenoid contents as well as the lutein contents, therefore, make it possible to deduce the contents of the above ingredients from the results of the quick test. The quick test also offers the advantage that it can be carried out quickly and with little effort and is, therefore, very interesting with regard to breeding and selection of varieties with a high carotenoid content. However, for an exact analysis of the most suitable varieties, the quick test is only suitable to a limited extent due to the correlation of 0.7 . We, therefore, recommend to test the $b$ value in early generation selection, but use the HPLC method for the late breeding generations. The relationship between zeaxanthin and the $b$ value is negligible due to the low average relative zeaxanthin content of $13.2 \%$ in durum wheat.
Table 7 Heritability $h^{2}$ and genetic variance $\sigma^{2}$ of the T. durum samples

\begin{tabular}{llll}
\hline & \multicolumn{2}{l}{ Heritability $h^{2}$} & Genetic variance $\sigma^{2}$ \\
\hline Lutein & 0.74 & & $* * *$ \\
Zeaxanthin & & 0.15 & n.s. \\
$\Sigma$ Carotenoids & 0.71 & & $* * *$ \\
$\beta$-Tocotrienol & & 0.52 & $* * *$ \\
$\Sigma$ Vitamin E & 0.38 & & $* *$ \\
\hline
\end{tabular}

$* p<0.05$ : significant correlation; $* * p<0.01$ : very significant correlation; $* * * p<0,001$ : highly significant correlation; n.s.: not significant

\section{Genetic variance and correlations to other quality parameters}

Further statistical tests and correlation analyses with other important quality properties of the T. durum samples were carried out with the obtained results. Table 7 shows data on heritability and genetic variability. Heritability describes which proportions of phenotypic expression are determined by genetic factors. This parameter was determined for contents of lutein, zeaxanthin, total carotenoids, $\beta$-tocotrienol, and vitamin E. Except for zeaxanthin, high values were determined here. From this, it can be concluded that contents of lutein and total carotenoids in particular are determined by the variety and that site conditions play only a minor role. The determined genetic variances are highly significant for contents of lutein, total carotenoid, and $\beta$-tocotrienol, 
Table 8 Correlations between $b$ value, contents of lutein, total carotenoids, $\beta$-tocotrienol, and vitamin E and other important quality parameters in the T. durum samples

\begin{tabular}{|c|c|c|c|c|c|c|c|c|}
\hline & Protein & Vitreousity & $b$ value & TKM & Lutein & $\Sigma$ Carotenoids & $\beta$-Tocotrienol & $\Sigma$ Vitamin $\mathrm{E}$ \\
\hline Protein & & $0.27 * * *$ & -0.14 n.s. & 0.14 n.s. & $-0.19 * *$ & $-0.15^{*}$ & -0.07 n.s. & -0.05 n.s. \\
\hline $\begin{array}{l}\text { Vitreousity } \\
b \text { value } \\
\text { TKM }\end{array}$ & & & $0.57 * * *$ & $\begin{array}{l}0.07 \text { n.s. } \\
-0.12 \text { n.s. }\end{array}$ & $\begin{array}{l}0.39 * * * \\
0.82 * * * \\
-0.25 * * *\end{array}$ & $\begin{array}{l}0.40 * * * \\
0.79 * * * \\
-0.26 * * *\end{array}$ & $\begin{array}{l}0.14 \text { n.s. } \\
0.22 * * \\
0.05 \text { n.s. }\end{array}$ & $\begin{array}{l}0.09 \text { n.s. } \\
0.19^{* *} \\
-0.02 \text { n.s. }\end{array}$ \\
\hline $\begin{array}{l}\text { Lutein } \\
\Sigma \text { Carotenoids } \\
\beta \text {-Tocotrineol } \\
\Sigma \text { Vitamin E }\end{array}$ & & & & & & $0.99 * * *$ & $\begin{array}{l}0.30 * * * \\
0.28 * * *\end{array}$ & $\begin{array}{l}0.31 * * * \\
0.29 * * * \\
0.97 * * *\end{array}$ \\
\hline
\end{tabular}

TKM thousand kernel mass

${ }^{*} p<0.05$ : significant correlation; $* * p<0.01$ : very significant correlation; $* * * p<0,001$ : highly significant correlation; n.s.: not significant

and are very significant for contents of vitamin E. Therefore, genetically caused significant differences between the individual varieties are present. Due to these results, it is possible to efficiently select varieties with high contents of lutein and total carotenoids by selecting specific varieties.

Correlation analyses were performed between the phytochemicals and other important quality parameters (see Table 8). These include protein content, vitreousity, and thousand kernel mass (TKM). The analyses showed that contents of lutein, total carotenoids, $\beta$-tocotrienol, and vita$\min \mathrm{E}$ were not correlated with the other important properties of the T. durum samples. Thus, varieties with a high content of lutein or total carotenoids can be selected in combination with other characteristics such as high yield or good pasta quality.

The results show that the levels of the measured lipophilic antioxidants vary depending on the environmental conditions of the site (soil and climate) and the chosen variety. The environmental impact is not stable and cannot be influenced by a farmer due to changing weather conditions each year. Furthermore, the variance due to different durum varieties was larger than the environmental variance for lutein and total carotenoids, making the choice of durum varieties with high contents interesting to warrant higher probabilities of these ingredients across the production chain. Although the general content of vitamin $\mathrm{E}$ is low in durum wheat, the high daily intake of pasta and the malnutrition of humans regarding vitamin $E$ make each increase due to varietal choice also for durum interesting [1-4, 52]. This holds also true for lutein, where a considerably higher amount is found in durum wheat. Finally, we elaborated a high genetic variance and heritability for lutein and sum of carotenoids and no negative correlations to important agronomic and quality traits in durum wheat. Thus, future durum breeding could deliver varieties with improved agronomy, quality, and increased contents of lutein and carotenoids.
Acknowledgements Open Access funding provided by Projekt DEAL. Thanks are given to Angelika Malarski for technical assistance.

\section{Compliance with ethical standards}

Conflict of interest The authors declare no conflict of interest.

Compliance with ethics requirements This article does not contain any studies with human or animal subjects.

Open Access This article is licensed under a Creative Commons Attribution 4.0 International License, which permits use, sharing, adaptation, distribution and reproduction in any medium or format, as long as you give appropriate credit to the original author(s) and the source, provide a link to the Creative Commons licence, and indicate if changes were made. The images or other third party material in this article are included in the article's Creative Commons licence, unless indicated otherwise in a credit line to the material. If material is not included in the article's Creative Commons licence and your intended use is not permitted by statutory regulation or exceeds the permitted use, you will need to obtain permission directly from the copyright holder. To view a copy of this licence, visit http://creativecommons.org/licenses/by/4.0/.

\section{References}

1. Shewry PR, Hey SJ (2015) The contribution of wheat to human diet and health. Food Energy Secur 4:178-202

2. Statista. Nudeln-Europa. (n.d.). https://de.statista.com/outlo ok/40060100/102/nudeln/europa. Accessed 20 Nov 2019

3. Bundesministerium für Ernährung und Landwirtschaft (Ed.). Deutschland, wie es isst - Der BMEL-Ernährungsreport 2017. Berlin. 2017

4. Statista. Pro-Kopf-Konsum von Pasta in ausgewählten Ländern weltweit im Jahr 2013 (in Kilogramm) https://de.statista.com/ statistik/daten/studie/479170/umfrage/pro-kopf-konsum-vonpasta-in-ausgewaehlten-laendern-weltweit/. Accessed 20 Nov 2019

5. Brandolini A, Castoldi P, Plizzari L, Hidalgo A (2013) Phenolic acids composition, total polyphenols content and antioxidant activity of Triticum monococcum, Triticum turgidum and Triticum aestivum: a two-years evaluation. J Cereal Sci 58:123-131

6. Halliwell B (1990) How to characterize a biological antioxidant. Free Radical Res 9:1-32 
7. Blokhina O, Virolainen E, Fagerstedt KV (2003) Antioxidants, oxidative damage and oxygen deprivation stress: a review. Ann Bot 91:179-194

8. Alvarez R, Vaz B, Gronemeyer H, de Lera AR (2014) Functions, therapeutic applications, and synthesis of retinoids and carotenoids. Chem Rev 114:1-125

9. Abdel-Aal EM, Young JC, Rabalski I, Hucl P, Fregeau-Reid J (2007) Identification and quantification of seed carotenoids in selected wheat species. J Agric Food Chem 55:787-794

10. Rehak M, Fric E, Wiedemann P (2008) Lutein und Antioxidantien zur Prävention der AMD. Ophthalmologe 105:37-45

11. Mares $\mathbf{J}$ (2016) Lutein and zeaxanthin isomers in eye health and disease. Annu Rev Nutr 36:571-602

12. Gong X, Draper CS, Allison GS, Marisiddaiah R, Rubin LP (2017) Effects of the macular carotenoid lutein in human retinal pigment epithelial cells. Antioxidants 6:100

13. Roberts JE, Dennison J (2015) The photobiology of lutein and zeaxanthin in the eye. J Ophthalmol 2015:687173

14. Westphal A, Böhm V (2015) Carotenoids-properties, distribution, bioavailability, metabolism and health effects. Ernahrungs Umschau 62:196-207

15. Murray IJ, Makridaki M, van der Veen RL, Carden D, Parry NR, Berendschot TT (2013) Lutein supplementation over a oneyear period in early AMD might have a mild beneficial effect on visual acuity: the CLEAR study. Invest Ophthalmol Vis Sci 54:1781-1788

16. Abdel-Aal EM, Akhtar H, Zaheer K, Ali R (2013) Dietary sources of lutein and zeaxanthin carotenoids and their role in eye health. Nutrients 5:1169-1185

17. Feeney J, O'Leary N, Moran R, O'Halloran AM, Nolan JM, Beatty S, Young IS, Kenny RA (2017) Plasma lutein and zeaxanthin are associated with better cognitive function across multiple domains in a large population-based sample of older adults: findings from the Irish longitudinal study on aging. J Gerontol A Biol Sci Med Sci 72:1431-1436

18. Li Y, Zhang Y, Liu X, Wang M, Wang P, Yang J, Zhang S (2018) Lutein inhibits proliferation, invasion and migration of hypoxic breast cancer cells via downregulation of HES1. Int J Oncol 52:2119-2129

19. Gong X, Smith JR, Swanson HM, Rubin LP (2018) Carotenoid lutein selectively inhibits breast cancer cell growth and potentiates the effect of chemotherapeutic agents through ROS-mediated mechanisms. Molecules 23:905

20. Chang J, Zhang Y, Li Y, Lu K, Shen Y, Guo Y, Qi Q, Wang W et al (2018) NrF2/ARE and NF- $\mathrm{NB}$ pathway regulation may be the mechanism for lutein inhibition of human breast cancer cell. Future Oncol 14:719-726

21. Szymanska R, Nowicka B, Kruk J (2017) Vitamin E - occurrence, biosynthesis by plants and functions in human nutrition. Mini-Rev Med Chem 17:1039-1052

22. Dysken MW, Sano M, Asthana S, Vertrees JE, Pallaki M, Llorente M, Love S, Schellenberg GD et al (2014) Effect of vitamin $\mathrm{E}$ and memantine on functional decline in Alzheimer disease: the TEAM-AD VA cooperative randomized trial. JAMA 311:33-44

23. Bundessortenamt (2018) Beschreibende Sortenliste Getreide, Mais, Öl- und Faserpflanzen, Leguminosen, Rüben. Zwischenfrüchte, Hannover

24. Mielke H, Rodemann B (2007) Triticum durum (Hartweizen), eine wenig angebaute Weizenart in Deutschland. Nachrichtenblatt des Deutschen Pflanzenschutzdienstes 59:113-117

25. Wagner S, Longin CF, Lewandowski L (2014) Heimischer Durumanbau-regional, nachhaltig aber zu wenig. Getreidetechnologie 68:36-39

26. Lampi AM, Nurmi T, Piironen V (2010) Effects of the environment and genotype on tocopherols and tocotrienols in wheat in the HEALTHGRAIN Diversity Screen. J Agric Food Chem 58:9306-9313

27. Sieber AN, Longin CFH, Würschum T (2017) Molecular characterization of winter durum wheat (Triticum durum) based on a genotyping-by-sequencing approach. Plant Genet Resour 15:36-44

28. Rapp M, Sieber AN, Kazman E, Leiser WL, Würschum T, Longin CFH (2019) Evaluation of the genetic architecture and the potential of genomics-assisted breeding of quality traits in two large panels of durum wheat. Theor Appl Genet 132:1873-1886

29. Sieber AN, Longin CF, Leiser WL, Würschum T (2016) Copy number variation of CBF-A14 at the Fr-A2 locus determines frost tolerance in winter durum wheat. Theor Appl Genet 129:1087-1097

30. Franke S, Fröhlich K, Werner S, Böhm V, Schöne F (2010) Analysis of carotenoids and vitamin $\mathrm{E}$ in selected oilseeds, press cakes and oils. Eur J Lipid Sci Technol 112:1122-1129

31. Ernawita WRA, Hesse J, Hipler U-C, Elsner P, Böhm V (2016) Carotenoids of indigenous citrus species from Aceh and its in vitro antioxidant, antidiabetic and antibacterial activities. Eur Food Res Technol 242:1869-1881

32. Longin CFH, Ziegler J, Schweiggert R, Koehler P, Carle R, Würschum T (2016) Comparative study of hulled (einkorn, emmer and spelt) and naked wheats (durum and bread wheat): agronomic performance and quality traits. Crop Sci 56:302-311

33. Longin CFH, Sieber AN, Reif JC (2013) Combining frost tolerance, high grain yield and good pasta quality in durum wheat. Plant Breed 132:353-358

34. Cochran WG, Cox GM (1957) Experimental designs. Wiley, New York

35. Stram DO, Lee JW (1994) Variance components testing in the longitudinal mixed effects model. Biometrics 50:1171-1177

36. Cullis BR, Smith AB, Coombes NE (2006) On the design of early generation variety trials with correlated data. J Agric Biol Envir St 11:381-393

37. Piepho HP, Möhring J (2007) Computing heritability and selection response from unbalanced plant breeding trials. Genetics 177:1881-1888

38. Gilmour AR, Gogel BJ, Cullis BR, Thompson R (2009) ASReml user guide. VSN International, Hemel Hempstead

39. Acquistucci R, Melini V, Carbonaro M, Finotti E (2013) Bioactive molecules and antioxidant activity in durum wheat grains and related millstream fractions. Int J Food Sci Nutr 64:959-967

40. Ramachandran A, Pozniak CJ, Clarke JM, Singh AK (2010) Carotenoid accumulation during grain development in durum wheat. J Cereal Sci 52:30-38

41. Fratianni A, Giuzio L, Di Criscio T, Zina F, Panfili G (2013) Response of carotenoids and tocols of durum wheat in relation to water stress and sulfur fertilization. J Agric Food Chem 61:2583-2590

42. Keleş Y, Öncel I (2002) Response of antioxidative defence system to temperature and water stress combinations in wheat seedlings. Plant Sci 163:783-790

43. Ziegler JU, Wahl S, Würschum T, Longin CF, Carle R, Schweiggert RM (2015) Lutein and lutein esters in whole grain flours made from 75 genotypes of 5 Triticum species grown at multiple sites. J Agric Food Chem 63:5061-5071

44. Van Hung P, Hatcher DW (2011) Ultra-performance liquid chromatography (UPLC) quantification of carotenoids in durum wheat Influence of genotype and environment in relation to the colour of yellow alkaline noodles (YAN). Food Chem 125:1510-1516

45. Werner S (2010) Carotinoide und Vitamin E in Hartweizen und daraus hergestellten Teigwaren-analytische, technologische und 
ernährungsphysiologische Aspekte. Dissertation. FriedrichSchiller-Universität Jena, Jena, Germany

46. Fratianni A, Irano M, Panfili G, Acquistucci R (2005) Estimation of color of durum wheat. Comparison of WSB, HPLC, and reflectance colorimeter measurements. J Agric Food Chem 53:2373-2378

47. Hussain A, Larsson H, Olsson ME, Kuktaite R, Grausgruber H (2012) Is organically produced wheat a source of tocopherols and tocotrienols for health food? Food Chem 132:1789-1795

48. Blanco A, Colasuonno P, Gadaleta A, Mangini G, Schiavulli $\mathrm{A}$, Simeone R, Digesù $\mathrm{AM}$, De Vita $\mathrm{P}$ et al (2011) Quantitative trait loci for yellow pigment concentration and individual carotenoid compounds in durum wheat. J Cereal Sci 54:255-264

49. Ziegler JU, Flockerzie M, Longin CF, Würschum T, Carle R, Schweiggert RM (2016) Development of lipophilic antioxidants and chloroplasts during the sprouting of diverse Triticum spp. J Agric Food Chem 64:913-922
50. Hentschel V, Kranl K, Hollmann J, Lindhauer MG, Böhm V, Bitsch R (2002) Spectrophotometric determination of yellow pigment content and evaluation of carotenoids by high performance liquid chromatography in durum wheat grain. J Agric Food Chem 50:6663-6668

51. Burkhardt S, Böhm V (2007) Development of a new method for the complete extraction of carotenoids from cereals with special reference to durum wheat (Triticum durum Desf.). J Agric Food Chem 55:8295-8301

52. Brigelius-Flohé R, Kelly FJ, Salonen JT, Neuzil J, Zingg JM, Azzi A (2002) The European perspective on vitamin E: current knowledge and future research. Am J Clin Nutr 76:703-716

Publisher's Note Springer Nature remains neutral with regard to jurisdictional claims in published maps and institutional affiliations. 